\title{
Goblet cell carcinomas of the appendix: rare but aggressive neoplasms with challenging management
}

\author{
Ashley K Clift', Oskar Kornasiewicz ${ }^{1,2}$, Panagiotis Drymousis', Omar Faiz ${ }^{1}$, Harpreet S Wasan', \\ James M Kinross ${ }^{1}$, Thomas Cecil ${ }^{4}$ and Andrea Frilling ${ }^{1}$ \\ ${ }^{1}$ Department of Surgery and Cancer, Imperial College London, London, UK \\ ${ }^{2}$ Department of Surgery, Warsaw Medical University, Warsaw, Poland \\ ${ }^{3}$ Department of Surgery, St Mark's Hospital, London, UK \\ ${ }^{4}$ Peritoneal Malignancy Unit, Basingstoke and North Hampshire Hospital, Basingstoke, UK
}

Correspondence should be addressed to A Frilling: a.frilling@imperial.ac.uk

\begin{abstract}
Goblet cell carcinomas (GCC) are a rare, aggressive sub-type of appendiceal tumours with neuroendocrine features, and controversy exists with regards to therapeutic strategy. We undertook a retrospective review of GCC patients surgically treated at two tertiary referral centres. Clinical and histopathological data were extracted from a prospectively maintained database. Survival analyses utilised Kaplan-Meier methodology. Twenty-one patients were identified ( 9 females). Median age at diagnosis was 55 years (range 32-77). There were 3, 6 and 9 grade 1, 2 and 3 tumours, respectively. One, 10, 5 and 5 patients had stage I, II, III and IV disease at diagnosis, respectively. There were 8, 10 and 3 Tang class A, B and C tumours, respectively. Index operation was appendectomy $(n=12)$, right hemicolectomy $(n=6)$ or resections including appendix/ right colon, omentum and the gynaecological system $(n=3)$. Eight patients underwent completion right hemicolectomy. Surgery for recurrence included small bowel resection $(n=2)$, debulking with peritonectomy and heated intraperitoneal chemotherapy, and hysterectomy and bilateral salpingo-oophorectomy (all $n=1)$. Median follow-up was 30 months (range 2.5-123). One-, 3- and 5-year OS was 79.4, 60 and 60\%, respectively. Mean OS (1-, 3-, and 5-year OS) for Tang class A, B and C tumours were 73.1 months (85.7, 85.7, 51.4\%), 83.7 months (all 66.7\%) and 28.5 months (66.7, 66.7\%, not reached), respectively. Chromogranin A/B and ${ }^{68} \mathrm{Ga}$-DOTATATE PET/CT were not useful in follow-up, but CEA, CA 19-9, CA 125 and ${ }^{18} \mathrm{~F}-\mathrm{FDG}$ PET/CT identified tumour recurrence. GCC must be clearly discriminated from relatively indolent appendiceal neuroendocrine neoplasms. ${ }^{18}$ F-FDG PET/CT and CEA/CA19-9/CA 125 are useful in detecting recurrence of GCC.
\end{abstract}

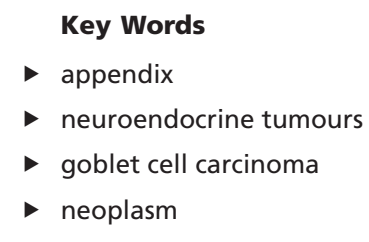

Endocrine Connections (2018) 7, 268-277

\section{Introduction}

Initially termed 'goblet cell carcinoids' (1), goblet cell carcinomas (GCC) are a rare sub-type of neoplasm arising from the appendix, accounting for less than 14\% of all appendiceal tumours (2). Whilst an 'intermediate' phenotype with regards to aggressiveness between appendiceal neuroendocrine neoplasms (ANEN) and adenocarcinoma has been described $(3,4)$, their incidence of 0.05/100,000/year (5) renders clinical experiencelimited. A median age at diagnosis of 58.9 years and no significant gender disparity have been reported in a systematic review of 600 patients (6). Historically often regarded as part of the spectrum of neuroendocrine neoplasms, GCC do http://www.endocrineconnections.org https://doi.org/10.1530/EC-17-0311
○ 2018 The authors Published by Bioscientifica Ltd
This work is licensed under a Creative Commons Attribution-NonCommercial-NoDerivatives 4.0 International License. 
indeed display a degree of neuroendocrine differentiation with expression of chromogranin A and B, synaptophysin, and allelic loss of chromosomes 11q, 16q and 18q has been observed in GCC, similar to NEN arising from the jejunum/ileum (7). However, their proliferation index as measured by Ki67 is often much higher than in intestinal NEN (8) and GCC display a more aggressive biology to the extent that they must be clearly delineated from NEN (4, $9)$. Such divergences in clinical behaviour are evident in the 5-year disease specific survivals with ANEN exceeding $90 \%$, whereas in GCC these range between 58\% and $81 \%$ $(10,11,12)$. Immunohistochemical distinction between the mucin-secreting GCC and ANEN may manifest as the stronger expression of CEA, CDX-2, CAM5.2 and cytokeratin (CK) in the former relative to the latter (13). In other histological analyses, an appreciable decrement in the expression of neuroendocrine markers in metastatic deposits of GCC in some patients has been reported (14). Although both ANEN and GCC are in general diagnosed incidentally at appendectomy, patients with GCC may present symptomatic and at advanced tumour stages in $10-63 \%$ of cases $(4,15)$.

The TNM staging of GCC follows the same system for ANEN as proposed by the Union Contre le Cancer/American Joint Committee on Cancer (UICC/AJCC) (4) (Table 1), which is supported in the consensus guidelines of the European Neuroendocrine Tumor Society (ENETS). The grading system replicates that of the ENETS/World Health Organization (WHO) system based on Ki67 index, i.e. grade $1=<2 \%$, grade $2=3-20 \%$, and grade $3=>20 \%$ (16). The TNM staging is a significant prognosticator, with 5 -year overall survivals in stage I, II, III and IV disease being 100, 76, 22 and 14\%, respectively, reported in a retrospective series of 57 GCC patients (17). A recently proposed histo-morphological classification by Tang and coworkers (15) classifies GCC as typical GCC and adenocarcinoma ex-GCC (Table 2). Typical GCC are deemed as 'group A' and display well defined goblet cell morphology without significant atypia. The latter group may be sub-divided into group B or group C, which demonstrate large irregular clusters of goblet or signet cell-type cells with destruction of the appendiceal wall, or exhibit poor differentiation, respectively. This classification has been shown to correlate with prognosis in both the original report and a recent case series $(15,18,19)$. For example, in the original report of Tang and coworkers (15), 5-year overall survivals in type A, B and C GCC were 96, 73 and 14\%, respectively.

Regarding treatment, controversy surrounds the optimal approach for small $(<1 \mathrm{~cm})$, non-metastatic GCC, specifically whether appendectomy is sufficient or an oncologic right-hemicolectomy is mandated $(9,20,21$, $22)$. The literature do not support any specific size cutoff, although some studies have suggested $10 \mathrm{~mm}$ as an appropriate arbiter of further resection (23). However, $<1 \mathrm{~cm}$ tumours are rarely encountered, and thus more aggressive therapy must often be considered utilising surgical and/or medical modalities. Right hemicolectomy is advocated as the standard surgical approach by the European Neuroendocrine Tumor Society (ENETS) and

Table 1 TNM staging system for goblet cell carcinomas of the appendix as per the UICC/AJCC guidelines (4) - these are identical to those for appendiceal neuroendocrine neoplasms.

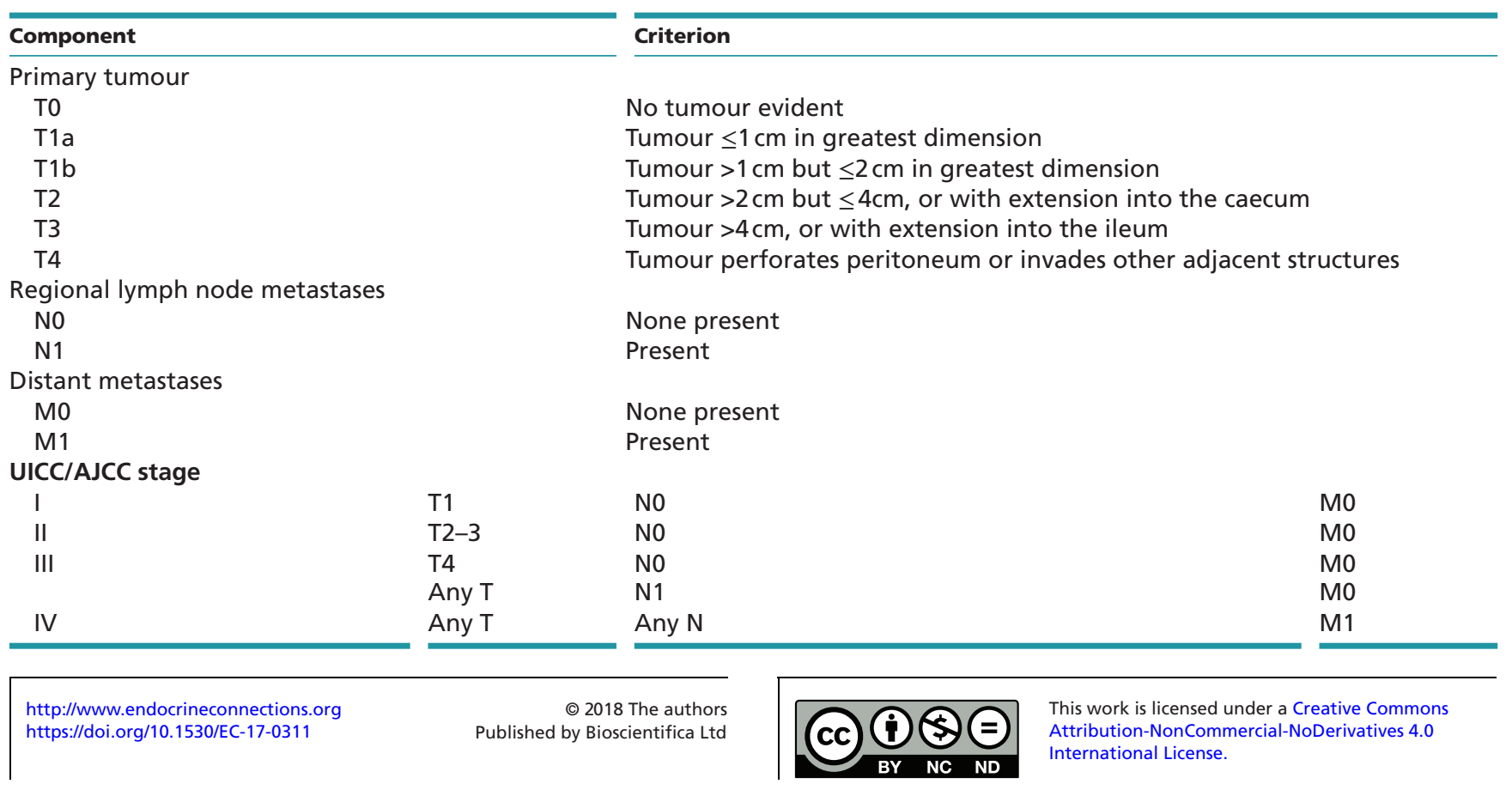


Table 2 Histopathological (Tang) classification of goblet cell carcinomas adapted from that as proposed by Tang and coworkers (15).

\begin{tabular}{|c|c|}
\hline Tang class & Designation \\
\hline A & Typical GCC \\
\hline B & Adenocarcinoma ex-GCC, signet cell type \\
\hline C & $\begin{array}{l}\text { Adenocarcinoma ex-GCC, poorly } \\
\text { differentiated carcinoma type }\end{array}$ \\
\hline
\end{tabular}

\section{Characteristics}

Well defined goblet cells (clusters or linear) with minimal atypia

Minimal or no desmoplasia

Minimal distortion of appendiceal wall

Goblet or signet ring-type cells in large, irregular clusters

Single file or single cell infiltrative pattern

Significant atypia

Desmoplasia evident with destruction of appendiceal wall

Minimum of focal evidence of goblet cell morphology

A component indistinguishable from poorly differentiated

adenocarcinoma (e.g. gland-forming, confluent sheets of signet ring cells)

GCC, goblet cell carcinoma.

North American Neuroendocrine Tumor Society (NANETS), although less than half of patients in population-based registries were reported to undergo this (23). The ENETS guidelines from 2012 advocated a completion right hemicolectomy within 3 months of appendectomy, and recommend ongoing 3-month interval staging for follow-up, although the optimal imaging modality is not clear (4). Somatostatin receptor-targeted imaging loses sensitivity with increasing proliferation and thus loss of neuroendocrine differentiation, whereas ${ }^{18}$ F-FDG PET may have more clinical utility. Regarding biochemical tests, use of the archetypal neuroendocrine markers chromogranins $\mathrm{A}$ and $\mathrm{B}$ is not recommended, and although CEA, CA 19-9 and CA 125 may be clinically useful, there is no definitive role (4). Selected patients with peritoneal dissemination may be considered for cytoreductive surgery and chemotherapy, or peritonectomy with hyperthermic intra-peritoneal chemotherapy (HIPEC), whilst the majority of patients with metastatic disease are treated with chemotherapy regimens akin to those utilised in colonic adenocarcinoma, i.e. with regimens based on 5-fluorouracil (5-FU) (9).

Here, we present our institutional experience with a cohort of 21 patients with GCC, all of which underwent surgical treatment as a component of a multimodal management strategy. Our aim was to identify clinically useful factors in the diagnosis and follow-up of GCC, and also to examine the role of aggressive surgical intervention in patients with GCC.

\section{Patients and methods}

We undertook a retrospective case review of individual patients treated for GCC at our centres - St Mark's Hospital London (London North West Healthcare NHS Trust), and Imperial College London Healthcare NHS Trust, which is an ENETS Centre of Excellence for Neuroendocrine

$$
\begin{array}{lr}
\text { http://www.endocrineconnections.org } & \odot 2018 \text { The authors } \\
\text { https://doi.org/10.1530/EC-17-0311 } & \text { Published by Bioscientifica Ltd }
\end{array}
$$

Tumours - between August 2006 and January 2017. The data collected from 2010 onwards were extracted from a prospectively maintained data base for neuroendocrine neoplasms. For inclusion in our study, patients had to be over 18 years of age, with histologically confirmed GCC and underwent surgical treatment. We are unaware of any patients with GCC that were not surgically treated. Individual patient cases were identified, with basic demographic, clinical and histopathological data extracted. Tumour grading was as per the ENETS guidelines (16), with grade 1, 2 and 3 defined as Ki67 <2, 3-20 and $>20 \%$, respectively. Staging was as per the UICC/AJCC TNM classification (Table 1 (4)). Histological reports were retrieved toassign 'Tang' classification(Table2) andreviewed by two dedicated NEN pathologists. The follow-up regime for our patients comprised: cross sectional imaging (CT, MRI liver), functional imaging $\left({ }^{68} \mathrm{Ga}\right.$-DOTATATE PET/CT, ${ }^{18} \mathrm{~F}$-FDG PET/CT), tumour markers (chromogranin A and B, CEA, CA125, and CA19-9). The type of modality used was tailored to the individual patient (e.g. ${ }^{68} \mathrm{Ga}$-DOTATATE PET/CT for G1 tumours only and ${ }^{18} \mathrm{~F}$-FDG PET/CT for G2 and G3). No other imaging modalities were used. Patients were followed up at 3-6 monthly intervals, which has been the institutional protocol since the beginning of the study period.

Kaplan-Meier methodology was utilised in the analysis of survival functions. Statistical calculations utilised R software, v3.3.2. The study was approved by the institutional review board at Imperial College London (REC07/MRE09/54). Consent was obtained from each patient after full explanation of the purpose and nature of all procedures used.

\section{Results}

Within the study period we identified 147 patients with appendiceal tumours (data not presented here) (24). 
Of them, 21 had GCC (9 female, 12 male). The median age at diagnosis was 55 years (range 32-77). Regarding UICC/AJCC tumour stage, there were: 1 stage I, 10 stage II, 5 stage III and 5 stage IV tumours. Tumour grade was available for 18 patients, with 3 G1, 6 G2 and 9 G3 tumours. Tang classification was available for all patients - there were 8, 10 and 3 patients with Tang type A, B and $\mathrm{C}$ tumours, respectively. In 10 patients, the primary tumour was located at the base of the appendix, with 5 in the body of the appendix, 3 at the appendiceal tip, and in 3 the location of the tumour was not reported. Basic clinicopathological characteristics are displayed in Table 3. The diagnosis of GCC was made only postoperatively in all patients, as is typical of this tumour type. Patients were primarily operated on for suspected appendicitis, due to lower abdominal pain with/without pyrexia, although one patient additionally had sub-acute bowel obstruction of initially uncertain aetiology. Patients found at index operation to have either large tumours and/or tumours displaying evidence of disease spread underwent operations other than simple appendectomy, i.e. right hemicolectomy or multivisceral resections, with the diagnosis of GCC evident on histology of resected tissues.

Regarding index operations, 12 underwent appendectomy, 6 underwent right hemicolectomy and 3

Table 3 Clinicopathological characteristics of the study cohort $(n=21)$.

\begin{tabular}{|c|c|}
\hline Parameter & $\boldsymbol{N}$ \\
\hline \multicolumn{2}{|l|}{ Gender } \\
\hline Male & 9 \\
\hline Female & 12 \\
\hline Median age at diagnosis (range) & $55(32-77)$ \\
\hline \multicolumn{2}{|l|}{ Tumour grade } \\
\hline G1 & $3 / 18$ \\
\hline G2 & $6 / 18$ \\
\hline G3 & $9 / 18$ \\
\hline \multicolumn{2}{|l|}{ Tumour stage at diagnosis ${ }^{c}$} \\
\hline I & 1 \\
\hline II & 10 \\
\hline III & 5 \\
\hline IV & 5 \\
\hline \multicolumn{2}{|l|}{ Tumour location within appendix ${ }^{d}$} \\
\hline Base & $10 / 18$ \\
\hline Body & $5 / 18$ \\
\hline Tip & $3 / 18$ \\
\hline \multicolumn{2}{|l|}{ Tang classificatione } \\
\hline A & 8 \\
\hline B & 10 \\
\hline C & 3 \\
\hline
\end{tabular}

a,dData available for 18 patients; ${ }^{b}$ as per ENETS guidelines (4); cas per AJCC/UICC system (4); eas per Tang and coworkers (15).

http://www.endocrineconnections.org https://doi.org/10.1530/EC-17-0311 had multivisceral resections of the lower gastrointestinal and gynaecological systems (Table 4 ). For the latter, these were: appendectomy+oophorectomy+omentectomy $(n=1), \quad$ appendectomy + hysterectomy + oophorectomy + omentectomy $\quad(n=1), \quad$ and right hemicolectomy + omentectomy + uterine resection $(n=1)$.

Following index operation, 6 patients received adjuvant cytotoxic chemotherapy with 5-FU-based regimens analogous to those for colorectal carcinoma. Specifically, these patients were treated in accordance with protocol for high-risk Dukes' B colorectal carcinoma. The regimen utilised was CAPOX, i.e. capecitabine (which is metabolised to 5-FU) and oxaliplatin. This was administered in 21-day cycles.

Some patients underwent a further 'completion' operation with the intention of disease control following histological confirmation of a GCC, and/or operation for treatment of imaging-identified disease recurrence. Details are presented in Table 4. Of the 12 patients undergoing index appendectomy, 8 patients underwent completion right hemicolectomy within 3 months - this includes one that later underwent tumour debulking with peritonectomy + HIPEC (performed at the Peritoneal Malignancy Unit, Basingstoke and North Hampshire Hospital, Basingstoke) for disease recurrence and another that underwent hysterectomy and bilateral salpingooophorectomy for evidence of residual disease at 18 months post-diagnosis. One patient who underwent index appendectomy later underwent a small bowel resection due to evidence of metastases, as did another who had initially received a right hemicolectomy as their index operation. The decision to operate was on the basis of deemed resectability on imaging, the general condition of the patient and patient's preference.

Of the patients receiving appendectomy only $(n=3)$, all had Tang A class GCC and two of them had G1 tumours. One patient that had a G2 (Ki67 10\%) GCC was found to harbour stage IV disease at first post-operative staging and died 5 months later following chemotherapy, whereas the remaining 2 are both alive without evidence of disease at 19 and 3 months follow-up, respectively. All 8 patients undergoing completion hemicolectomy were alive and disease free at last follow-up (median 35.5 months, range 30-121 months). There was no 30-day mortality, and Clavien-Dindo (25) grade 1 morbidity was seen in two patients.

Serum chromogranin A and/or B were not elevated in any patients throughout follow-up, and thus was not useful for monitoring for disease recurrence. In the patients demonstrating disease recurrence, at least one

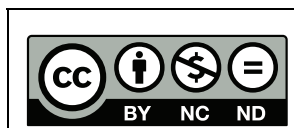

This work is licensed under a Creative Commons Attribution-NonCommercial-NoDerivatives 4.0 International License. 


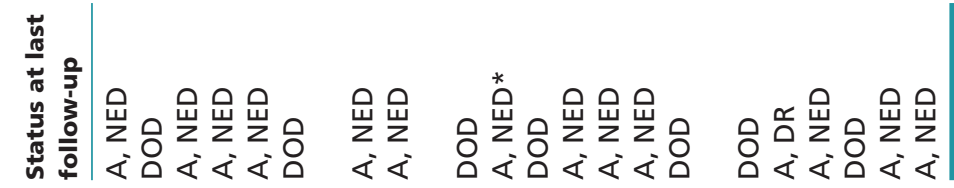

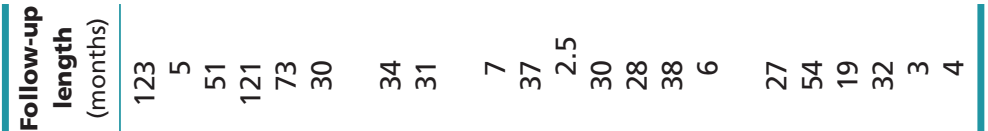
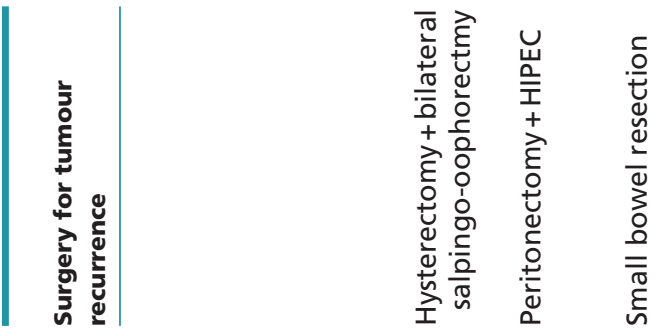

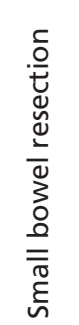
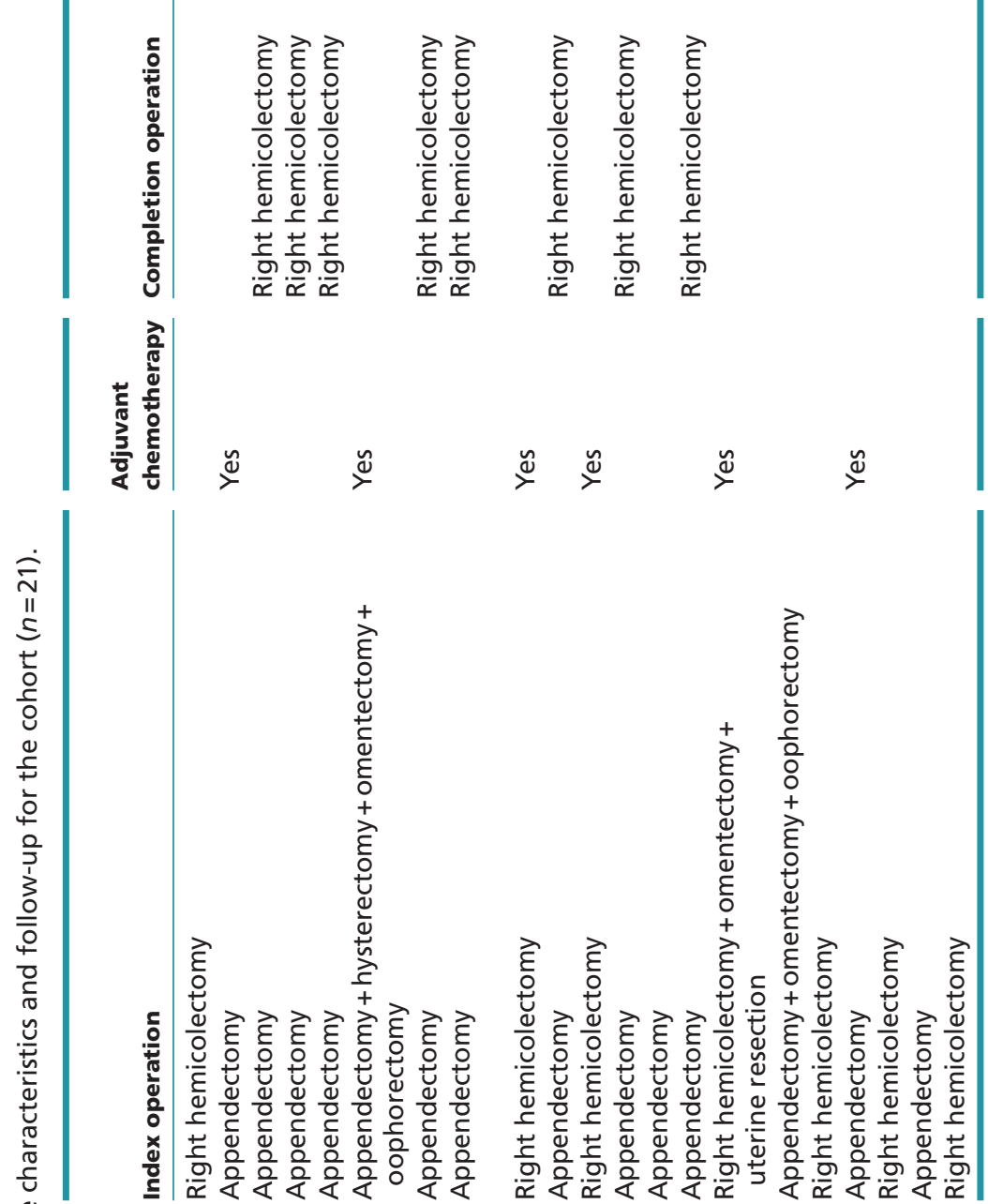

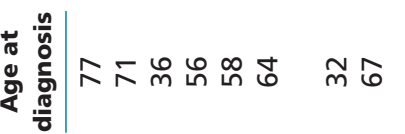

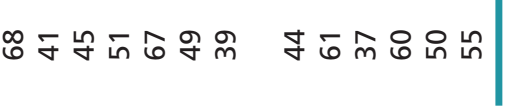


of CEA, CA 19-9 and CA 125 was elevated, however not all markers were measured in all patients. No evidence of disease recurrence was ever identified on ${ }^{68} \mathrm{Ga}$-DOTATATE PET/CT, whereas positive findings on ${ }^{18} \mathrm{~F}-\mathrm{FDG}$ PET/CT were observed in all patients that had recurrent disease. ${ }^{18}$ F-FDG PET/CT was therefore clearly the superior imaging modality and had tangible ramifications on treatment strategy. For example, in one patient that underwent index appendectomy and then completion hemicolectomy, pathologic CA 19-9 level 12 months post-hemicolectomy and adjuvant chemotherapy was suspicious for recurrence, which was evident on ${ }^{18} \mathrm{~F}$-FDG PET/CT (Fig. 1). The patient then underwent debulking, peritonectomy and HIPEC but had another elevation of CA 19-9 and increased uptake on ${ }^{18} \mathrm{~F}-\mathrm{FDG}$ PET/CT 12-months following this third intervention (Fig. 1). This patient's peritoneal disease was stage 3 (as per the Gilly classification) and her peritoneal cancer index was 12 .

The median follow-up for the cohort was 30 months (range 2.5-123 months), during which there were 7 disease-related patient deaths, all of which had either G2 or G3 tumours. Four patients died from disseminated tumour recurrence within 2 years of initial treatment, all of which had received adjuvant chemotherapy. Median OS was not reached, whereas mean OS for the cohort was 80.3 months, and 1-, 3- and 5-year OS was 79.4, 60 and $60 \%$, respectively. One-, 3- and 5-year DFS was 94.7, 74.2 and $74.2 \%$, respectively. Regarding Tang classification, mean OS (and 1-, 3-, and 5-year OS) for Tang class A, B and $\mathrm{C}$ tumours were 73.1 months $(85.7,85.7,51.4 \%)$, 83.7 months (all 66.7\%) and 28.5 months $(66.7,66.7 \%$, not reached), respectively. Given the small numbers of patients, a comparative sub-group survival analysis was not performed.

\section{Discussion}

The management of patients with GCC is challenging due to a poor understanding of their biological behaviour, and their rarity precluding evidence-based therapeutic algorithms for optimal treatment. As GCC are typically diagnosed incidentally subsequent to appendectomy, the role of diagnostic biomarkers is limited in this field. However, elucidation of clinically useful biomarkers for monitoring disease status or recurrence is a major unmet need. Whilst the limitations of chromogranin A and B in GCC are clearly recognised to the extent that consensus exists regarding their lack of utility in GCC (4), alternative markers are posited without clear evidence of sensitivity.

$$
\begin{array}{lr}
\text { http://www.endocrineconnections.org } & \odot 2018 \text { The authors } \\
\text { https://doi.org/10.1530/EC-17-0311 } & \text { Published by Bioscientifica Ltd }
\end{array}
$$

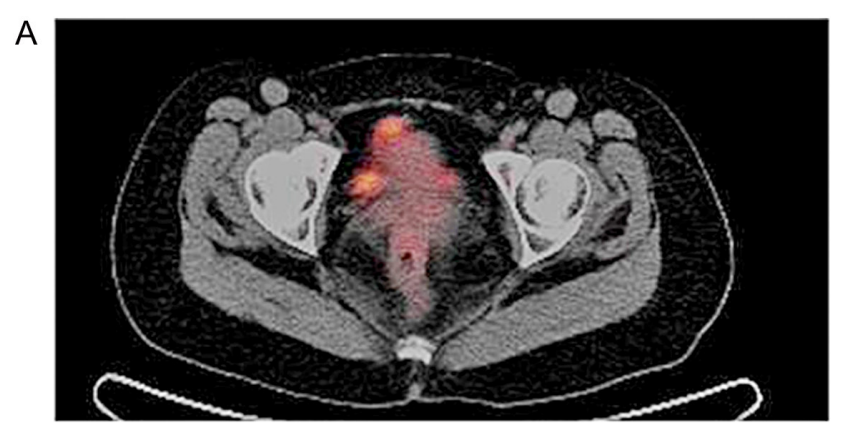

B
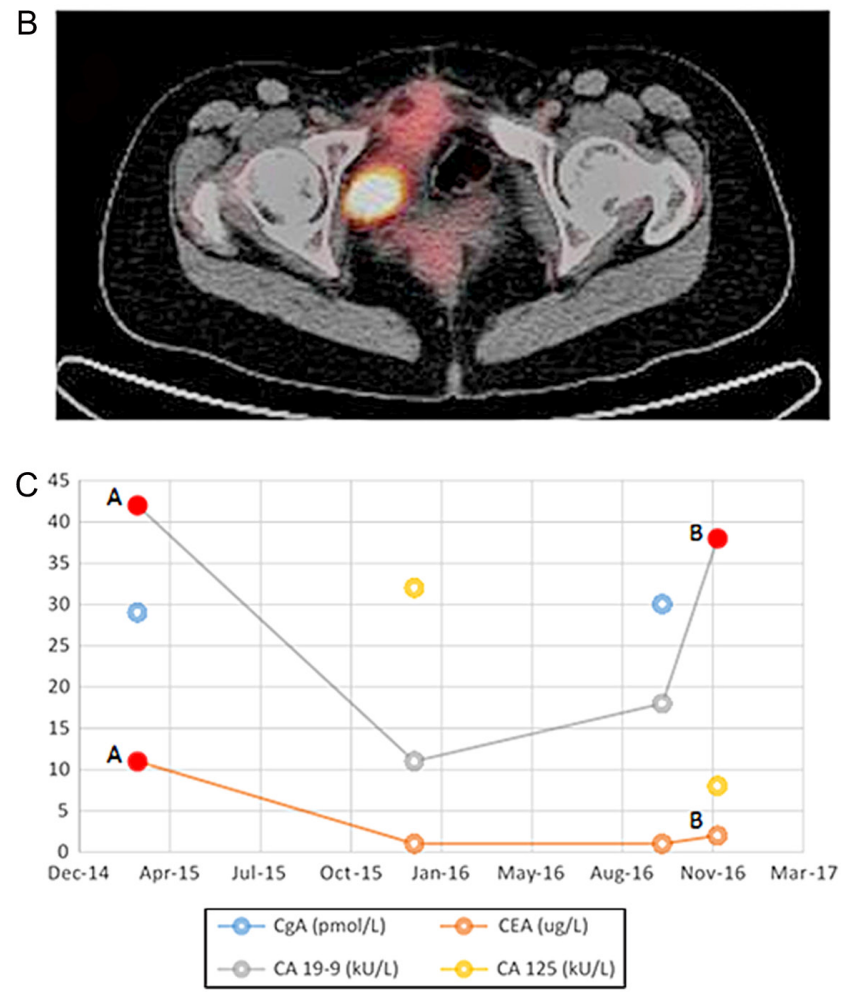

Figure 1

Imaging and biochemical findings in recurrent disease in a 41 year old patient with grade 3 , Tang class $C$ goblet cell carcinoma. The patient underwent appendectomy as the index operation, with completion right hemicolectomy and chemotherapy, and thereafter peritonectomy with heated intra-peritoneal chemotherapy due to recurrence evident on biochemistry and imaging. Top $(\mathrm{A})={ }^{18} \mathrm{~F}-\mathrm{FDG}$ PET/CT at 12 months post-hemicolectomy and chemotherapy showing multifocal recurrent disease in the pelvis. Central $(B)={ }^{18} \mathrm{~F}-\mathrm{FDG}$ PET/CT 12 months postperitonectomy again demonstrating pelvic disease recurrence. Bottom (C) = tumour marker dynamics during follow-up period $-A$ and $B$ correspond to the timing of images $A$ and $B$, respectively. Red filled circles represent an elevation of that tumour marker.

The ENETS consensus guidelines of 2012 suggest CEA, CA-125 and CA 19-9 as possible markers (4). Indeed, these were able to identify disease recurrence in our cohort, yet the full panel was not examined in every patient, and the optimal collective of assays is yet to be identified. The fact that the archetypal neuroendocrine markers

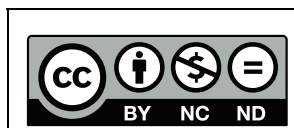
This work is licensed under a Creative Commons
Attribution-NonCommercial-NoDerivatives 4.0 International License. 
(i.e. chromogranins) were ineffective follow-up tools, yet CEA, CA 19-9 and CA 125 were able to detect disease recurrence is reflective of the adenocarcinoma component of GCC driving the disease's aggressive behaviour.

Whilst recent guidelines almost universally advocate surgical therapy as the mainstay of treatment for GCC, there is either a lack of consensus regarding most effective surgical approach or poor quality data forming a basis for recommendations. As is the case with appendiceal NEN, right hemicolectomy may occupy a role within the treatment concept for GCC (26), yet the indications are debatable $(9,27)$, which is notable given the generally appreciated increased aggressiveness of GCC compared to ANEN, but also the morbidity of the procedure, especially in elderly patients.

Retrospective case series differ in their support of right hemicolectomy in localised GCC, although a meta-analysis by Varisco and coworkers including 100 patients from 13 case series with GCC failed to find a significant benefit of hemicolectomy relative to appendicectomy alone in this setting, and also reported failure rates (in terms of disease control) of appendectomy alone and extended resection of $7 \%$ and $10 \%$, respectively (28). A recent institutional case series by Lamarca and coworkers examined prognostic factors in their cohort of 74 patients wherein $64 \%$ of those treated with curative intent underwent right hemicolectomy (18). The group failed to identify any effect of right hemicolectomy on disease-free survival indeed their data also suggested a higher risk of relapse with right hemicolectomy, with relapse occurring in $50 \%$ of those receiving hemicolectomy vs $21 \%$ of patients who did not $(P=0.037)$. Furthermore, they failed to identify any specific size cut-off at which right hemicolectomy is associated with improved prognosis. Contrastingly, in a Danish cohort of 83 patients reported by Olsen and coworkers (19), non-radical surgery for the primary tumour was identified as a negative prognosticator, and Lamarca and coworkers actually concluded that appendectomy alone is only justifiable in patients with completely resected Tang class A, stage I/II tumours that are unable to undergo surgery due to comorbidities conferring unacceptable surgical risk (18). In our study, we followed an aggressive approach, as only three patients (all Tang class A) had received appendectomy alone. One of these patients died within 5 months of appendectomy, and the other two were not candidates for further resection but remain disease-free at last follow-up. Of our 6 patients that received isolated completion hemicolectomy, none had displayed disease recurrence within a follow up of 63.5 months (range 30-121 months), suggesting adequate disease control.

Additional challenging considerations in the surgical treatment of GCC is the management of recurrent disease, which may involve management of the peritoneal cavity and also the use of prophylactic salpingo-oophorectomy in female patients. The peritoneum is the commonest site of metastasis, assumed to be via trans-coelomic spread, and is also the commonest site of disease relapse in reported series (18). This observation has been utilised as justification by some groups for consideration of a staging laparoscopy (18) and consecutive cytoreductive resection with HIPEC $(18,29)$, and also prophylactic bilateral salpingooophorectomy in female GCC patients $(6,15)$. Clearly in the latter setting, pre-menopausal women diagnosed with GCC would require careful counselling regarding the non-uniformly accepted benefits of disease control against infertility. In our cohort, we did not uniformly proceed with prophylactic oophorectomy. Three female patients identified to have stage IV disease at diagnosis underwent hysterectomy and/or oophorectomy, and one who initially underwent appendectomy with completion hemicolectomy for a stage II, G3 tumour received later hysterectomy and salpingo-oophorectomy due to ovarian metastases. Thus, although our data cannot advocate universal bilateral oophorectomy, it highlights the risk of metachronous metastases in female patients and call for detailed counselling with individual patients.

The morbidity and mortality from different surgical approaches for GCC is poorly documented in the available literature - although a 12\% rate of wound infection following cytoreductive surgery/HIPEC was reported by Lamarca and coworkers there was no clear documentation regarding morbidity following hemicolectomy (18). We believe that the favourably low morbidity encountered in our cohort justifies the 'aggressive' approach to GCC that we are following. However, we are aware that the number of patients in this case series does not enable a strong recommendation. Whilst previous retrospective case series have analysed heterogeneous cohorts insofar as including patients undergoing both surgical treatment with curative intent and palliative non-surgical treatment options, our study comprised patients that were all managed surgically within the course of their disease.

The precise role and benefits of chemotherapy in GCC have not been extensively tested under the auspices of prospective trials. This is again attributable to the rarity of this tumour type precluding prospective trials of chemotherapeutics. Goblet cell carcinomas may be treated with regimens extrapolated from those utilised 
in colorectal adenocarcinomas, including FOLFOX (5-fluorouracil and oxaliplatin) or CAPOX (capecitabine and oxaliplatin). Such treatment selection is predicated by the clinical behaviour of GCC being more congruous with adenocarcinoma than with neuroendocrine tumour. In their series from the Mayo clinic, Pham and coworkers failed to identify a significant difference in survival between patients undergoing adjuvant chemotherapy, and those who did not (17). In the series of Lamarca and coworkers, 18 patients underwent adjuvant chemotherapy, and 24 underwent palliative chemotherapy during their treatment (18). The commonest regimen for both was FOLFOX. This group observed no effect of adjuvant chemotherapy on disease-free survival or relapse rate in any GCC stage sub-group. For palliative chemotherapy there was a $60 \%$ disease control rate, and a $14 \%$ rate of partial response as assessed on radiological imaging. The median estimated progression-free survival for palliative chemotherapy was 5.3 months.

Overall, our study of 21 surgically-treated patients with GCC clearly demonstrates the necessity of treating patients with GCC in specialist centres within a multidisciplinary setting of specialist histopathologists, radiologists/nuclear medicine physicians, surgeons familiar with complex abdominal procedures and advanced technology, and oncologists. Relative to ANEN with which GCC was until recently often regarded as indistinct from, GCC are highly aggressive tumours and clear histopathological discrimination between the two is crucial. Of particular note is the rate of advanced disease between ANEN and GCC - in our centre, under 10\% of patients with ANEN (data not presented here) had nodal metastases with over 99\% of ANEN G1 in nature (24), whereas $47.6 \%$ of our GCC patients had at least nodal metastases at initial diagnosis, and $83.3 \%$ were G2/3 tumours. The clear distinction between ANEN and GCC is crucial as the latter require more aggressive therapy and surveillance. Figure 2 demonstrates a management algorithm based on the experience from our centres and also the aforementioned literature.

Despite the aggressive surgical approach in our patient cohort with most patients undergoing multiple surgical procedures (with/without adjuvant chemotherapy) including advanced techniques such as peritonectomy and HIPEC, 1-, 3- and 5-year overall survivals in our cohort were 79.4, 60 and 60\%, respectively, and almost a fifth of patients died of disseminated tumour recurrence within 2 years. These outcomes call for further research

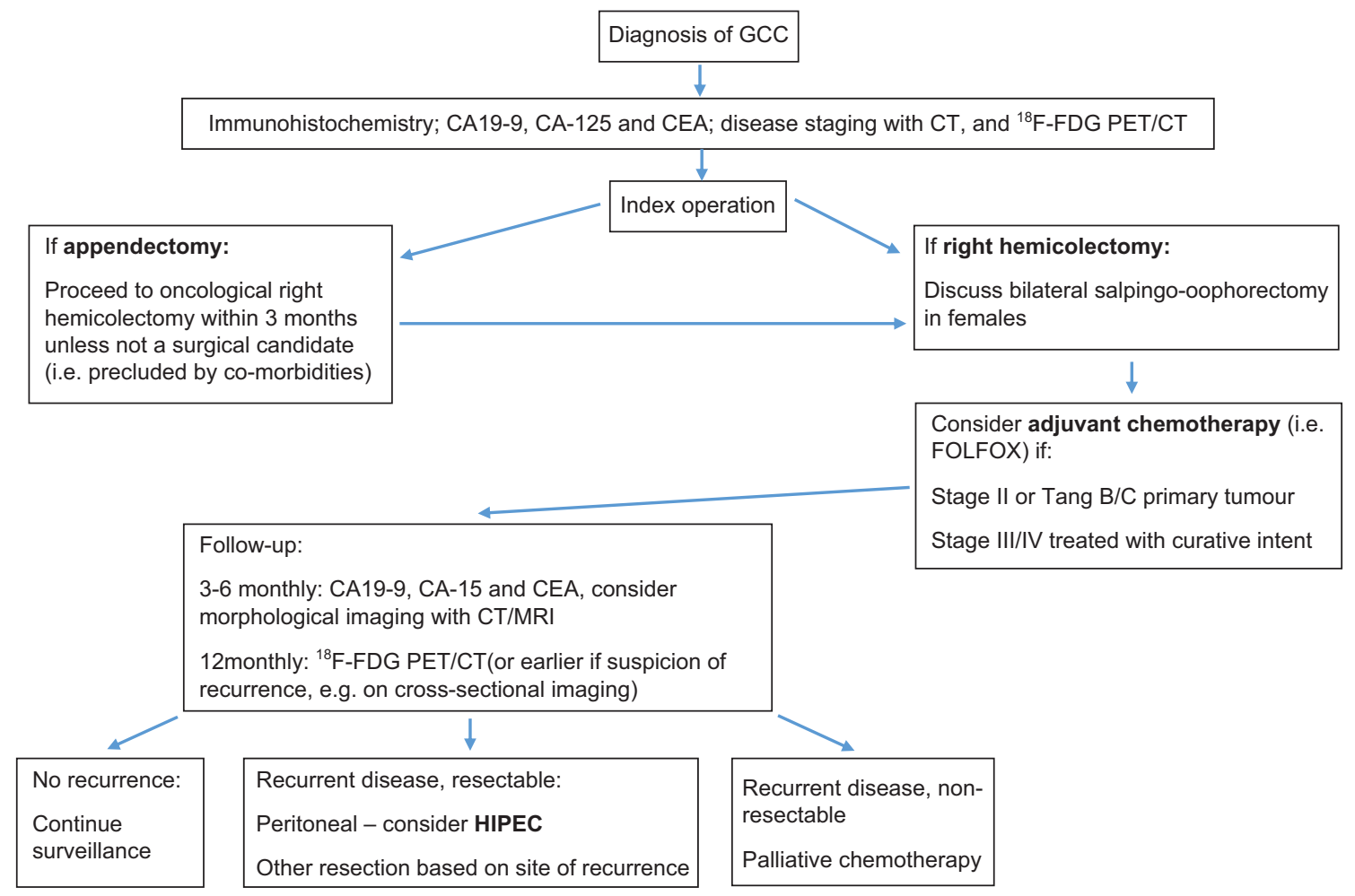

Figure 2

Algorithm for the management of patients with goblet cell carcinomas. HIPEC, heated intra-peritoneal chemotherapy.

(C) 2018 The authors
Published by Bioscientifica Ltd

http://www.endocrineconnections.org

https://doi.org/10.1530/EC-17-0311

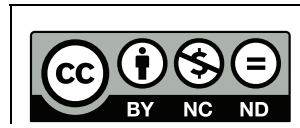

This work is licensed under a Creative Commons Attribution-NonCommercial-NoDerivatives 4.0 International License. 
with an aim to better elucidate the nature of this disease and develop novel treatment strategies. We are aware that the small size of our cohort, the retrospective nature of our study and the risk of selection bias introduced by our referral pattern present limitations.

Ideally, the exact role of right hemicolectomy in localised disease, the role of chemotherapy, the most useful follow-up protocols and also the benefits of aggressive peritoneal management in GCC would be elucidated by prospective trial studies. However, given the scarcity of this tumour type, such studies would present stark logistical challenges. Collaborative multi-centre studies of the molecular biology of this rare tumour type will be required to identify putative novel predictive and prognostic markers, and also identify targets for precision therapy in GCC.

\section{Declaration of interest}

The authors declare that there is no conflict of interest that could be perceived as prejudicing the impartiality of the research reported.

\section{Funding}

This work was supported by the Dr Heinz-Horst Deichmann Foundation.

\section{Acknowledgements}

This paper was presented at Digestive Disease Week, Chicago, USA, 6-9 May 2017.

\section{References}

1 Subbuswamy SG, Gibbs NM, Ross CF \& Morson BC. Goblet cell carcinoid of the appendix. Cancer 197434 338-344. (https://doi.org/10.1002/1097-0142(197408)34:2<338::AIDCNCR2820340218>3.0.CO;2-W)

2 Goede AC, Caplin ME \& Winslet MC. Carcinoid tumour of the appendix. British Journal of Surgery 200390 1317-1322. (https://doi. org/10.1002/bjs.4375)

3 Rossi RE, Luong T-V, Caplin ME, Thirlwell C, Meyer T, GarciaHernandez J, Baneke A, Conte D \& Toumpanakis C. Goblet cell appendiceal tumors - management dilemmas and longterm outcomes. Surgical Oncology 201524 47-53. (https://doi. org/10.1016/j.suronc.2015.01.001)

4 Pape U-F, Perren A, Niederle B, Gross D, Gress T, Costa F, Arnold R, Denecke T, Plöckinger U, Salazar R, et al. ENETS Consensus Guidelines for the management of patients with neuroendocrine neoplasms from the jejuno-ileum and the appendix including goblet cell carcinomas. Neuroendocrinology 201295 135-156. (https://doi. org/10.1159/000335629)

5 Holt N \& Grønbæk H. Goblet cell carcinoids of the appendix. Scientific World Journal 20132013 article id 543696. (https://doi $\operatorname{org} / 10.1155 / 2013 / 543696)$

6 Pahlavan PS \& Kanthan R. Goblet cell carcinoid of the appendix. World Journal of Surgical Oncology 20053 36. (https://doi. org/10.1186/1477-7819-3-36)
7 Stancu M, Wu T-T, Wallace C, Houlihan PS, Hamilton SR \& Rashid A. Genetic alterations in goblet cell carcinoids of the vermiform appendix and comparison with gastrointestinal carcinoid tumors. Modern Pathology 200316 1189-1198. (https://doi.org/10.1097/01. MP.0000097362.10330.B1)

8 Jiang Y, Long H, Wang W, Liu H, Tang Y \& Zhang X. Clinicopathological features and immunoexpression profiles of goblet cell carcinoid and typical carcinoid of the appendix. Pathology and Oncology Research 201117 127-132. (https://doi.org/10.1007/ s12253-010-9291-5)

9 Clift AK \& Frilling A. Neuroendocrine, goblet cell and mixed adeno-neuroendocrine tumours of the appendix: updates, clinical applications and the future. Expert Review of Gastroenterology and Hepatology 201711 1-11.

10 Turaga KK, Pappas SG \& Gamblin TC. Importance of histologic subtype in the staging of appendiceal tumors. Annals of Surgical Oncology 201219 1379-1385. (https://doi.org/10.1245/s10434-0122238-1)

11 Hsu C, Rashid A, Xing Y, Chiang Y-J, Chagpar RB, Fournier KF, Chang GJ, You YN, Feig BW, Cormie JN, et al. Varying malignant potential of appendiceal neuroendocrine tumors: importance of histologic subtype. Journal of Surgical Oncology 2013107 136-143. (https://doi.org/10.1002/jso.23205)

12 McCusker ME, Coté TR, Clegg LX \& Sobin LH. Primary malignant neoplasms of the appendix: a population-based study from the surveillance, epidemiology and end-results program, 1973-1998. Cancer 200294 3307-3312. (https://doi.org/10.1002/cncr.10589)

13 van Eeden S, Offerhaus GJA, Hart AAM, Boerrigter L, Nederlof PM, Porter E \& van Velthuysen ML. Goblet cell carcinoid of the appendix: a specific type of carcinoma. Histopathology $2007 \mathbf{5 1} 763-773$. (https://doi.org/10.1111/j.1365-2559.2007.02883.x)

14 Yan TD, Brun EA \& Sugarbaker PH. Discordant histology of primary appendiceal adenocarcinoid neoplasms with peritoneal dissemination. Annals of Surgical Oncology 200815 1440-1446. (https://doi.org/10.1245/s10434-007-9754-4)

15 Tang LH, Shia J, Soslow RA, Dhall D, Wong WD, O’Reilly E, Qin J, Paty P, Weiser MR, Guillem J, et al.Pathologic classification and clinical behavior of the spectrum of goblet cell carcinoid tumors of the appendix. American Journal of Surgical Pathology 200832 1429-1443. (https://doi.org/10.1097/PAS.0b013e31817f1816)

16 Rindi G, Klöppel G, Couvelard A, Komminoth P, Körner M, Lopes JM, McNicol AM, Nilsson O, Perren A, Scarpa A, et al. TNM staging of midgut and hindgut (neuro) endocrine tumors: a consensus proposal including a grading system. Virchows Archiv 2007 451 757-762. (https://doi.org/10.1007/s00428-007-0452-1)

17 Pham TH, Wolff B, Abraham SC \& Drelichman E. Surgical and chemotherapy treatment outcomes of goblet cell carcinoid: a tertiary cancer center experience. Annals of Surgical Oncology 200613 370-376. (https://doi.org/10.1245/ASO.2006.02.016)

18 Lamarca A, Nonaka D, Lopez Escola C, Hubner RA, O'Dwyer S, Chakrabarty B, Fulford P \& Valle JW. Appendiceal goblet cell carcinoids: management considerations from a reference peritoneal tumour service centre and ENETS centre of excellence. Neuroendocrinology 2016103 500-517. (https://doi. org/10.1159/000440725)

19 Olsen IH, Holt N, Langer SW, Hasselby JP, Grønbæk H, Hillingsø J, Mahmoud M, Ladekarl M, Iversen LH, Kjær A, et al. Goblet cell carcinoids: characteristics of a Danish cohort of 83 patients. PLoS ONE 201510 e0117627. (https://doi.org/10.1371/journal. pone.0117627)

20 Park K, Blessing K, Kerr K, Chetty U \& Gilmour H. Goblet cell carcinoid of the appendix. Gut 199031 322-324. (https://doi. org/10.1136/gut.31.3.322)

21 Gordon R, Burns K \& Friedlich M. Goblet cell carcinoid of the appendix. Canadian Journal of Surgery 200548 251-252. http://www.endocrineconnections.org https://doi.org/10.1530/EC-17-0311
(C) 2018 The authors Published by Bioscientifica Ltd
This work is licensed under a Creative Commons Attribution-NonCommercial-NoDerivatives 4.0 International License. 
22 Byrn JC, Wang J-L, Divino CM, Nguyen SQ \& Warner RRP. Management of goblet cell carcinoid. Journal of Surgical Oncology 200694 396-402. (https://doi.org/10.1002/jso.20587)

23 Bucher P, Gervaz P, Ris F, Oulhaci W, Egger J-F \& Morel P. Surgical treatment of appendiceal adenocarcinoid (goblet cell carcinoid). World Journal of Surgery 200529 1436-1439. (https://doi.org/10.1007/ s00268-005-7958-y)

24 Pawa N, Clift AK, Osmani H, Drymousis P, Cichocki A, Flora R, Goldin R, Patsouras D, Baird A, Malczewska A, et al. Surgical management of patients with neuroendocrine neoplasms of the appendix: appendectomy or more? Neuroendocrinology 2017 [epub]. (https://doi.org/10.1159/000478742)

25 Dindo D, Demartines N \& Clavien P-A. Classification of surgical complications: a new proposal with evaluation in a cohort of 6336 patients and results of a survey. Annals of Surgery $2004240205-213$ (https://doi.org/10.1097/01.sla.0000133083.54934.ae)
26 Toumpanakis C, Standish RA, Baishnab E, Winslet MC \& Caplin ME. Goblet cell carcinoid tumors (adenocarcinoid) of the appendix. Diseases of the Colon and Rectum 200750 315-322. (https://doi. org/10.1007/s10350-006-0762-4)

27 Roy P \& Chetty R. Goblet cell carcinoid tumors of the appendix: an overview. World Journal of Gastrointestinal Oncology 20102 251-258. (https://doi.org/10.4251/wjgo.v2.i6.251)

28 Varisco B, McAlvin B, Dias J \& Franga D. Adenocarcinoid of the appendix: is right hemicolectomy necessary? A meta-analysis of retrospective chart reviews. American Surgeon 200470 593-599.

29 McConnell YJ, Mack LA, Gui X, Carr NJ, Sideris L, Temple WJ, Dubé P, Chandrakumaran K, Moran BJ, Cecil TD, et al. Cytoreductive surgery with hyperthermic intraperitoneal chemotherapy: an emerging treatment option for advanced goblet cell tumors of the appendix. Annals of Surgical Oncology 201421 1975-1982. (https:// doi.org/10.1245/s10434-013-3469-5)

Received in final form 10 January 2018

Accepted 15 January 2018

Accepted Preprint published online 15 January 2018 http://www.endocrineconnections.org https://doi.org/10.1530/EC-17-0311
(C) 2018 The authors Published by Bioscientifica Ltd 